\title{
Applying ant colony algorithm to identify ecological security patterns in megacities
}

Jian Peng a, b, ${ }^{\text {, }}$, Shiquan Zhao ${ }^{\text {b }}$, Jianquan Dong ${ }^{\text {a }}$, Yanxu Liu ${ }^{c}$, Jeroen Meersmans ${ }^{\text {d }}$, Huilei Li ${ }^{\text {a }}$, Jiansheng $\mathrm{Wu}^{\mathrm{b}}$

a Laboratory for Earth Surface Processes, Ministry of Education, College of Urban and Environmental Sciences, Peking University, Beijing 100871, China

${ }^{\mathrm{b}}$ Key Laboratory for Environmental and Urban Sciences, School of Urban Planning \& Design, Shenzhen Graduate School, Peking University, Shenzhen 518055, China

c State Key Laboratory of Earth Surface Processes and Resource Ecology, Faculty of Geographical Science, Beijing Normal University, Beijing 100875, China

${ }^{\mathrm{d}}$ School of Water, Energy and Environment, Cranfield University, Bedford MK43 0AL, United Kingdom

\begin{abstract}
Ecological security patterns composed of ecological sources and corridors provide an effective approach to conserving natural ecosystems. Although the direction of ecological corridors have been identified in previous studies, the precise range remains unknown. To address this crucial gap, ant colony algorithm and kernel density estimation were applied to identify the range and restoration points of ecological corridors, which is important for natural conservation and ecological restoration. In this case study of Beijing City, ecological sources were identified based on habitat importance and landscape connectivity. The results showed that, in total $3119.65 \mathrm{~km}^{2}$ of ecological land had been extracted as ecological sources, which were mainly located in the northern, northwestern and northeastern mountainous areas. The identified key ecological corridor covered an area of $198.86 \mathrm{~km}^{2}$, with $567.30 \mathrm{~km}^{2}$ for potential ecological corridors, both connecting the ecological sources. 34 key points were also identified with priority in restoring ecological corridors.
\end{abstract}

Key words: Ant colony algorithm; kernel density estimation; range of ecological corridors; ecological restoration points; ecological security patterns; urban planning

\footnotetext{
${ }^{*}$ Corresponding author. College of Urban and Environmental Sciences, Peking University, Beijing 100871, China Email address: jianpeng@urban.pku.edu.cn
} 


\section{Introduction}

Although urbanization is considered as the most important driving factor for economic development, it also results in nonnegligible eco-environmental issues (He et al., 2014; Li et al., 2011; Peng et al., 2017; Kong et al., 2017). Sustainable development refers to the integrity and balance of the development sustainability in economic, social, and environmental dimensions. Thus, ensuring ecological security and sustainability has become nowadays an important challenge for regional sustainable development, resulting in a rapidly growing interest in identifying ecological security patterns as an effective natural conservation approach. As ecological security patterns are based on the interactions between landscape patterns and ecological functions as well as processes, they are crucial for the provisioning of ecosystem services and thus the maintaining of ecological sustainability (Su et al., 2016; Teng et al., 2011). Generally speaking, ecological security patterns can characterize current integrity and health status of natural ecosystems as well as long-term potential in biodiversity conservation and landscape ecological restoration (Yu 1996). In contrast to other similar concepts, such as urban growth boundary (Long et al., 2013) and planetary boundary (Rockström et al., 2009) which are both based on ecological thresholds, the ecological security patterns are theoretically based on the principles of landscape ecology, and are focused on spatial or functional connectivity among important patches, in view of corridors.

In identifying ecological security patterns, there are mainly two steps, i.e. identifying ecological sources, and ecological corridors. In details, composed of important natural habitat patches, there are two methods to identify ecological sources. One is to directly select nature reserves, scenic spots and large patches of ecological land (Aminzadeh and Khansefid 2010; Vergnes et al., 2013), and the other is to develop an assessment system based on habitat importance and landscape connectivity (Lin et al., 2017; Mandle et al., 2016; Pierik et al., 2016). Comparatively speaking, the latter is more accepted due to its focusing on quantification and functionality. Although there are many methods to identify ecological corridors (Rouget et 
al., 2006; Parks et al., 2013; Bhowmik et al., 2015; Brás et al., 2013), the minimum cumulative resistance (MCR) model is the most widely applied because it can simulate the process of ecological flow with considering landscape heterogeneity and connectivity (Hepcan and Özkan, 2011; Wang et al., 2008). However, MCR model can effectively delineate the direction of ecological corridors, but cannot provide any information about the range of ecological corridors (Zhang et al., 2017b). The strategic points are also not focused on, while they are important for maintaining and improving ecological corridors in the context of urban planning.

The ant colony algorithm, proposed by Colorni et al. (1991), can simulate the process that ants detect the optimal routes between their nests and nearby food resources (Bonabeau et al., 2000). More precisely, when ants are looking for optimal routes, they will leave the pheromone along the way to satisfy the demand for building continuous pathways ( $\mathbf{L i}$ and Chan 2007; Zhang et al., 2017a). As the pheromone diffuses in space, it provides a quantitative support to spatially identify the range in which the information flow takes place. Through the guidance of pheromone, a positive feedback mechanism is formed between ants, which improves the calculating robustness (Dorigo et al., 1996). As to the application, ant colony algorithm was firstly used to successfully solve the Travelling Salesman Problem (Dorigo et al., 1997). In recent years, ant colony algorithm had been gradually applied across different fields of research, including groundwater depth monitoring ( $\mathbf{L i}$ et al., 2007), food production network protection (Golding et al., 2017), and the optimization of irrigation scheduling (Nguyen et al., 201). Hence, the application of ant colony algorithm might be helpful in identifying the range of ecological corridors.

Along with ecological land loss and natural habitat degradation in Beijing City due to rapid urban expansion, such ecosystem services as net primary productivity (NPP) and carbon storage capacity decreased considerably (Peng et al., 2016; He et al., 2016). Composed of key ecological patches and corridors determining regional ecological process and thus sustainability, ecological security patterns have been regarded as one of the win-win approaches to coordinate 
urbanization and natural conservation. Thus, taking Beijing City as a case study area, ant colony algorithm was applied to identify ecological security patterns in megacities. In this case study of Beijing City, ecological sources were identified by combining assessments of habitat importance with landscape connectivity. More specifically, the aims were to identify ecological sources combining habitat importance assessment and landscape connectivity assessment, to determine spatial direction ecological corridors using MCR model, and to identify the range as well as associated key points of ecological corridors with the application of ant colony algorithm and kernel density estimation.

\section{Materials and Methods}

\subsection{Study area and data source}

The study area, Beijing City $\left(115^{\circ} 25^{\prime}-117^{\circ} 30 \mathrm{E}, 39^{\circ} 28^{\prime}-41^{\circ} 05^{\prime} \mathrm{N}\right)$, covers an area of $16410.54 \mathrm{~km}^{2}$, and is divided into 16 districts (i.e. Dongcheng, Xicheng, Haidian, Chaoyang, Fengtai, Mentougou, Shijingshan, Fangshan, Tongzhou, Shunyi, Changping, Daxing, Huairou, Pinggu, Yanqing, and Miyun) (Fig. 1). The west, north and northeast of Beijing City are characterized by mountainous terrain, covering $62 \%$ of the total area, whereas the remaining $38 \%$ is located in the North China Plain, mainly covering the southeastern part of the study area (Fig. 1). The population growth in Beijing City has been remarkable over recent years. As a consequence it has become one of the largest cities globally. More precisely, the number of permanent residents has grown rapidly from c. 13 million in 2000 to more than 21 million in 2015. Urban impervious surface area has gradually occupied green space and expanded from the edge of town to the surrounding countryside (Wang et al., 2014). As a result, there are serious conflicts between limiting natural capital provision and increasing social demanding for ecosystem services (Peng et al., 2015). 


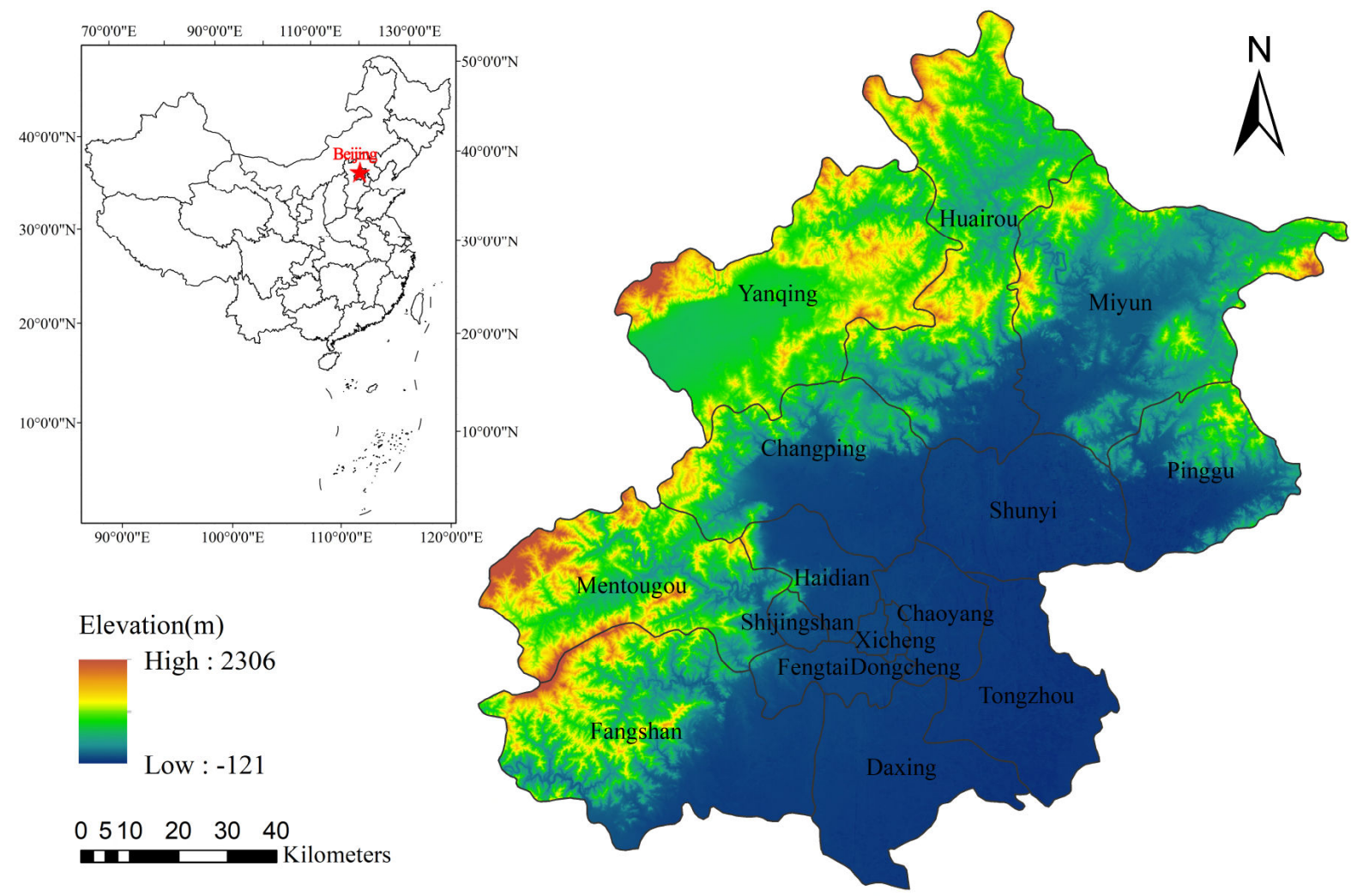

Fig.1 Geographical location and elevation of Beijing City

Six main datasets were used in this study: (1) Land use and land cover (LULC) data were retrieved from the database of global surface coverage at a spatial resolution of $30 \mathrm{~m}$ (http://www.globeland30.org); (2) Road network data collected from Open Street Map (http://www.openstreetmap.org/); (3) ASTER GDEMV2 data obtained from USGS Earth Explorer website at a spatial resolution of $30 \mathrm{~m}$ (https://earthexplorer.usgs.gov/); (4) MODIS raster data products downloaded from NASA-USGS platform (https://lpdaac.usgs.gov/), representing (i) evapotranspiration, (ii) normalized difference vegetation index (NDVI), and (iii) leaf-area index (LAI) data, which were resampled to $30 \mathrm{~m} \times 30 \mathrm{~m}$ pixels;(5) Meteorological station data covering Beijing City, Tianjin City, and Hebei Province obtained from China's meteorological data sharing service system (http://data.cma.cn/), including the data of (i) daily precipitation, and (ii) daily average wind speed. The precipitation data was interpolated using spline function to convert point data into raster data with $30 \mathrm{~m} \times 30 \mathrm{~m}$ pixels;(6) Global 
near-surface $\mathrm{PM}_{2.5}$ concentrations averaged raster data of 2010 provided by the Atmospheric Composition Analysis Group platform (http://fizz.phys.dal.,ca/ atmos/martin/), which was calculated using an optimal estimation model based on MODIS aerosol data with geographic weighted regression correction based on $\mathrm{PM}_{2.5}$ surface detection data.

\subsection{Methods}

The overall methodological framework followed in this study can be divided into two parts (Fig. 2). Firstly, it is to quantify habitat importance in view of ecosystem services, and to measure landscape connectivity, which were subsequently followed by the identification of ecological sources through combining habitat importance and landscape connectivity. Secondly, the MCR, colony algorithm and kernel density estimation are successively applied to identify key ecological corridor, potential ecological corridors, and key restoration points of ecological corridors. More precisely, MCR was used to determine the basic spatial direction of ecological corridors, whereas ant colony algorithm allowed the identification of the range of ecological corridors. And the kernel density estimation was applied post processing, in order to determine the range and extract key restoration points of the identified ecological corridors.

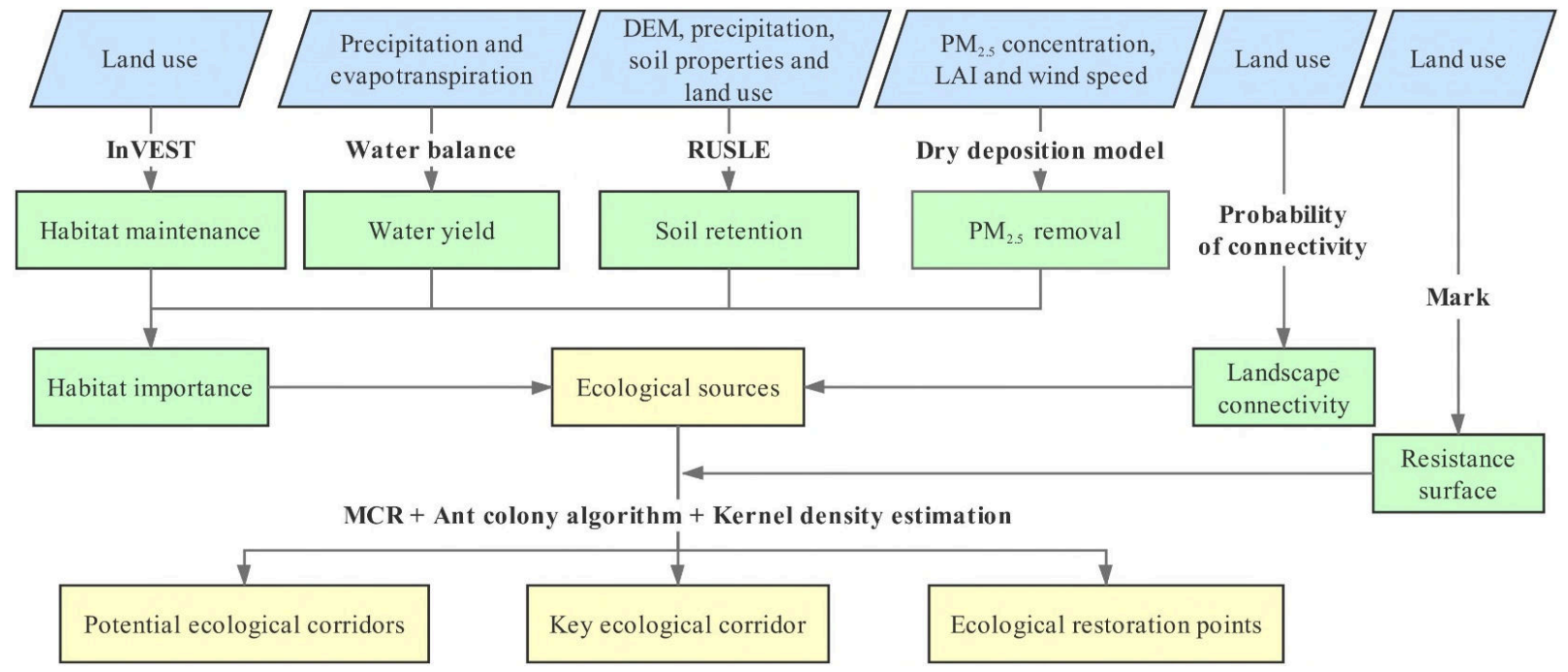

Fig.2 Methodological framework (blue boxes = source data; green boxes = calculation processes, yellow boxes $=$ identification results; information in bold $=$ software packages or models / methods) 


\subsubsection{Ecological source identification based on habitat importance and landscape connectivity}

As the main component of ecological security patterns, ecological sources refer to the most important patches determining both the provisioning of regional ecosystem services and the maintaining of ecological processes in the landscape. Hence, ecological sources can be identified based on habitat importance and landscape connectivity. In the past decades, urbanization in Beijing City had resulted in a series of negative ecological effects such as habitat loss, water shortage, soil erosion, and air pollution (Asgarian et al., 2015; Jenerette et al., 2010; Wu et al., 2013). Facing with these ecological issues, four corresponding ecosystem services were considered to assess habitat importance, i.e. the services of habitat maintenance, water yield, soil retention, and $\mathrm{PM}_{2.5}$ removal. Habitat importance was quantified through overlaying the normalized four ecosystem services with equal weights. For ecosystem services and habitat importance, five levels were divided using natural break method. Furthermore, landscape connectivity could be measured using the index of probability of connectivity (PC) across the region (Carranza et al., 2012). Subsequently, the normalized habitat importance and landscape connectivity with equal weights were combined to quantify protection importance. Quantile classification method was applied to divide protection importance into five levels, with the highest level of very important identified as ecological sources.

Habitat maintenance. High habitat quality can provide good habitat conditions, and thus increases biodiversity. Habitat quality module of InVEST was usually used to quantify the service of habitat maintenance (Cotter et al., 2017, Lin et al., 2017). Within this module, construction land including urban and rural settlements, mining sites, roads and railways, all characterized by significant human activities, was regarded as threat sources, whereas other land use types were set as ecological land. More precisely, three key factors were needed, i.e. (i) distance to the threat sources, (ii) weight of threat sources effects, and (iii) the sensitivity of associated ecological land. The specific parameters for these key factors were adopted from 
previous studies (i.e. Sharp et al. 2018 and Polasky et al. 2011).

Water yield. Due to the suitability across a wide range of regions and environments as well as spatial-temporal scales (Jia et al., 2014), water balance method has been widely used to assess the service of water yield. In this study, water yield is defined as the difference between precipitation and evapotranspiration as follows:

$$
Q=P-E
$$

Where $Q$ is annual water yield, $P$ is annual total precipitation, and $E$ is annual total evapotranspiration, using MODIS 2010 yearly composite product.

Soil retention. Due to essential role in retaining to vegetation growth, soil is one of the key elements of terrestrial ecosystems. However, soil is susceptible to human activities, which may lead to the change of soil quality and quantity soil through a wide range of environmental threats such as soil erosion and degradation. Thus, soil retention is an important ecosystem service to be considered in assessing habitat importance. The Revised Universal Soil Loss Equation (RUSLE) was applied to assess soil retention (Van Oost et al., 2000), which was as follows:

$$
A=R \times K \times L S \times(1-C \times P)
$$

Where $A$ is annual soil retention, $R$ is rainfall erosivity factor, $K$ is soil erodibility factor, $L S$ is slope length and steepness factor, $P$ is conservation practices factor, and $C$ is vegetation coverage factor (Chen and Zha 2016; Rozos et al., 2013).

$\mathbf{P M}_{2.5}$ removal. Air pollution in Beijing City, especially the concentration of air fine particulate matter $\left(\mathrm{PM}_{2.5}\right)$ has increased significantly over recent years. As a result, vegetation reduction of $\mathrm{PM}_{2.5}$ is one of the most important ecosystem services. In this study, the $\mathrm{PM}_{2.5}$ vegetation reduction model proposed by Nowak et al. (2013) was used, which was applicable in non-rainfall days.

$$
\begin{gathered}
I=F \times A \times T \times(1-R) \\
F=V_{d} \times C \times 3600
\end{gathered}
$$

Where $I$ is $\mathrm{PM}_{2.5}$ removal, $A$ is leaf surface area, $T$ is assessment period, $R$ is $\mathrm{PM}_{2.5}$ resuspension 
rate, $F$ is PM2.5 removal flux, $V_{d}$ is deposition velocity of $\mathrm{PM}_{2.5}$, and $C$ is $\mathrm{PM}_{2.5}$ concentration. $R$ and $V_{d}$ are directly related to wind speed (Nowak et al., 2013).

Landscape connectivity. Landscape connectivity can promote or limit wildlife's movement or ecological processes between patches, and thus reflect the importance of different patches within a given landscape. In this study, the index of Probability of Connectivity (PC) was used to measure landscape connectivity (Carranza et al., 2012; Peng et al., 2018). By using the PC calculation model of Saura et al. (2009), the probability of landscape connectivity index, expressed as a figure between 0 and 1, was obtained, indicating the chance of connectivity between the patches as a function of distance. More precisely, for all the patches of ecological land, the effect on the overall landscape connectivity of a single patch is calculated by comparing PC index before and after the removal of the patch, which is shown as follows:

$$
\begin{gathered}
I=\frac{\sum_{i=0}^{n} \sum_{j=0}^{n} a_{i} a_{j} P_{i j}^{*}}{A_{L}^{2}} \\
d I(\%)=100 \times \frac{I-I_{\text {remove }}}{I}
\end{gathered}
$$

Where $n$ is the number of ecological patches, $a_{i}$ and $a_{j}$ are the area of patch $i$ and patch $j, A_{L}$ is

the area of the overall landscape, $P_{i j}^{*}$ is the probability of movement between patch $i$ and patch $j$, $I$ is the overall landscape connectivity index, $I_{\text {remove }}$ is the overall landscape connectivity index after removal of the assessing patch, and $d I(\%)$ is the relative importance of the assessing patch to landscape connectivity. The higher the value of $d I(\%)$, the more important that specific patch is for the overall landscape connectivity. ArcGIS 10.x plug-in "Conefore Inputs" as well as the “Conefore Sensinode 2.2" software were used for calculating the importance of ecological patches in landscape connectivity.

\subsubsection{Ecological corridor identification based on MCR, ant colony algorithm and kernel} density estimation

The ant colony algorithm is often used to conduct the path-finding analysis with the process 
in which ants communicate by leaving synthetic pheromone when seeking from their nests to food resources (Zhang et al., 2017a). In this context, it is necessary to recognize that the various pixels are spatially interconnected in order to overcome the following typical computational issues in ant colony algorithm: (1) If each ant's movement is completely random, it can easily happen that one ant goes into an infinite loop in local optimal solution; (2) "No data" pixels may decrease the efficiency of ant colony algorithm to a large extent; and (3) As the active space of pheromone is discrete, it can be hard to determine the ecological corridors' borders.

To solve the three above-mentioned issues, this study proposed a methodological improvement to the algorithm's traditional modus operandi, through dividing the ecological corridor identification procedure into the following three main steps: (1) Data preparation, including the construction of ecological resistance surface based on land use types; (2) Ant colony path-finding, including the identification of the basic spatial direction of ecological corridors based on MCR, as well as building the pixels direction control layer based on the Euclidean space distance method for running the ant colony algorithm; (3) Data postprocessing, i.e. (i) analyzing spatial range of ecological corridors based on ant colony pheromone residues, (ii) extracting the range and key restoration points of ecological corridors with the application of kernel density estimation, and thus (iii) constructing ecological security patterns across the region.

Data preparation. The ecological resistance surface, as used in many studies, represents the resistance to the movement of different species in space (Gao et al., 2017; Zhang et al., 2017b). In this study, construction land was set to have the highest ecological resistance coefficient, with the lowest for forest land. In details, the resistance coefficients of forest land, orchard, grassland, water body, cultivated land, unused land, country road, main road, railway, and other construction land, were set as 1, 3, 7, 15, 20, 50, 70, 90, 90 and 100, respectively (e.g. Peng et al., 2018). In the ant colony algorithm, the ecological resistance, as being presented in the resistance surface, was considered as the distance that the ant needed to travel so as to reach a given pixel from the starting pixel. Hence, the pixel with the highest resistance was considered to 
be the farthest from the ant.

Ant colony path-finding. By means of MCR, the basic direction of corridors between two patches of ecological sources in a region was determined. This will be the first general spatial orientation of the ecological corridor. Subsequently, multiple buffer zones with different radius from the first direction line were considered as search area, in order to conduct the ant colony path-finding. The Euclidean distance to the direction lines of ecological corridor were then calculated within the buffer zones. The direction of each spatial pixel with the same Euclidean distance was oriented parallel to the ecological corridors' orientation. More precisely, the direction code in this study was based on the location of the eight neighboring pixels in a $3 \times 3$ pixel cluster. The latter allowed to direct the ants into the next pixel, supposing that the angle between the ant's direction in the current pixel and that in the next pixel must be less than or equal to $90^{\circ}$. The direction layer could ensure the ants did not go into an infinite loop when searching for the optimal route. Then probabilistic transition rule, local updating rule, and global updating rule, were applied to let each ant move between source points, i.e. geometric center of ecological source patches, over a range of connecting pixels across the whole region. In each iteration, 10 ants were set to start the path-finding algorithm. A maximum of 60,000 iterations were considered. However, a global optimal solution was identified whenever 100 ants were able to reach the end-point, or the optimal solution had not been updated during the latest 200 iterations.

Data postprocessing. The results of ant colony path-finding are characterized with spatial distribution of the ant's pheromone, which in turn will be used to construct the density surface for the whole region using the method of kernel density estimation. Kernel density estimation is one of the most commonly used non-parametric estimation methods used in probability theory in order to make an estimation of unknown probability density functions (Brunsdon, 1995; Shi, 2010). More specifically, the Rosenblatt-Parzen kernel estimation was used in this study (Brunsdon, 1995, eq. (7) \& (8)):

$$
\hat{f}=\frac{1}{n h} \sum_{i=1}^{n} k(s, h)
$$




$$
k(s, h)=\frac{1}{\sqrt{2 \pi} h} \exp \left(-\frac{s^{2}}{2 h^{2}}\right)
$$

Where $\hat{f}(x)$ is the estimated value of the probability density, $h(h>0)$ is the bandwidth, $s$ is the distance from the point $x$ to the sample point $X_{i}$, i.e. $s=|x-X|, n$ is the number of sample points, and $k(s, h)$ is the kernel function, usually using the Gaussian-Kernel-Function.

More precisely, the kernel density surface was obtained through conducting variable-bandwidth kernel density estimation. All the kernel density values, except from 0 , were classified into nine categories using the quantile classification method. Comparing spatial characteristics of the kernel density surface and the ecological resistance surface, the reclassification threshold of kernel density surface was obtained which made the identified ecological corridors could not only reflect the range and direction changes in the resistance surface, but also maintain the connectivity between ecological source patches. Finally, the areas with kernel density higher than the threshold were identified to be part of ecological corridors.

\section{Results}

\subsection{Habitat importance}

Spatial distribution of habitat maintenance service across the whole region was shown in Fig. 3a. In general, habitat quality gradually increased as it moved away from the central urban area, which was characterized as the ascending service importance from urban center to urban-rural fringe and thus to rural center. There were also threatening sources in rural areas, but their negative impacts might be limited. Because of their relatively discrete distribution, the extent and range of the threatening to biodiversity in the surrounding habitats were far less than those in urban areas.

Water yield service was mapped, as shown in Fig. 3b. It was obvious that water yield in Shijingshan District was mostly at the lowest level (over $98 \%$ of the total area) similar in Chaoyang District, Fengtai District and Haidian District. However, Tongzhou District had 
relatively high water yield, with the important level and very important level accounting for $59.70 \%$ and $23.47 \%$ of total area respectively. In contrast, Pinggu District and Shunyi District were mostly occupied with the level of very important, with the highest $94.10 \%$ of area proportion for Pinggu District.

Fig. 3c showed spatial distribution of soil retention service in the study area. It could be found that the districts of Mentougou, Pinggu, Miyun, Huairou, and Yanqing, all far away from Beijing's city center, had the highest area proportion of the level of very important. Especially in Mentougou District, it was characterized with the highest importance in Beijing City, with the level of very important and important accounting for $8.88 \%$ and $25.15 \%$ of the total area, respectively. In the districts of Fangshan, Changping, and Shijingshan, soil retention was relatively low, with the lowest level of very unimportance covering $50-75 \%$ of the total area. For the other districts, it was over $85 \%$, or even $100 \%$.

Fig. 3d mapped the service of $\mathrm{PM}_{2.5}$ removal. The districts near the city center were generally characterized by the level of very unimportant, accounting for more than $60 \%$ of the total area, such as Haidian District, Shijingshan District, Fengtai District, and Chaoyang District. In the districts with flat area, such as Daxing District, Tongzhou District and Shunyi District, the level of unimportant accounted for about $70 \%$ of the total area, although they were not near the city center. However, in the mountain districts, i.e. the districts of Pinggu, Changping, Huairou, Mentougou, Miyun, and Yanqing, accumulated area proportion of the levels of important and very important was all over $30 \%$.
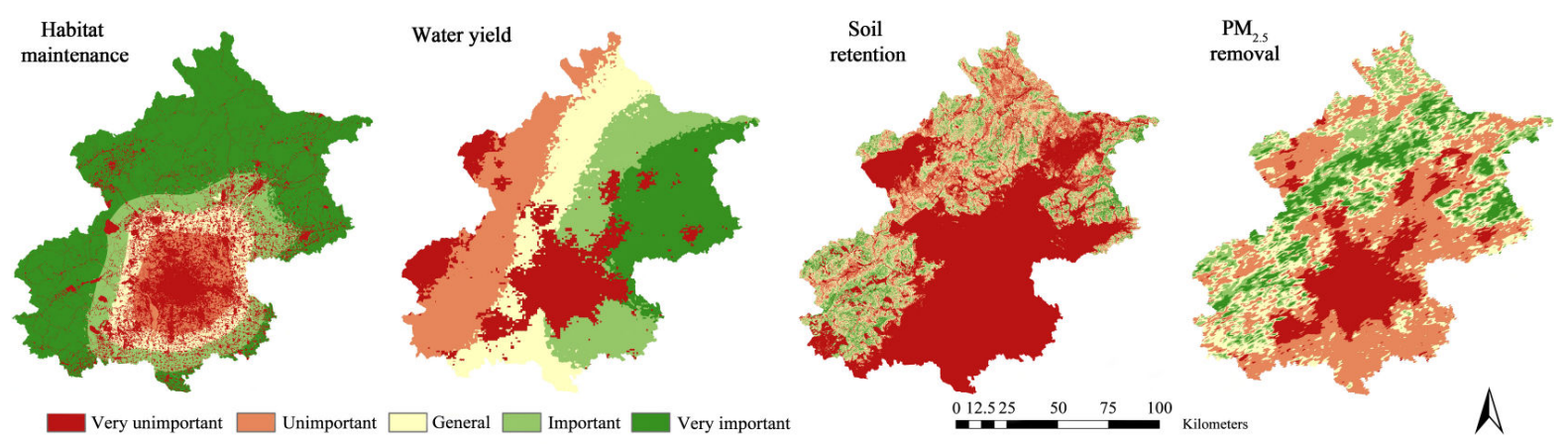

Fig.3 Spatial distribution of ecosystem services in Beijing City 


\subsection{Ecological sources}

Through overlaying the importance of ecosystem services, an overall habitat importance map could be obtained (Fig. 4a). It could be found that the moderate importance levels i.e. unimportant level, general level, and important level, covered large areas of the districts of Shunyi, Changping and Tongzhou, with about 30\% for area proportion of each level. The level of very important was mostly distributed in Pinggu District, Miyun District and Huairou District, accounting for c. $89.70 \%$ of the importance level.

Fig. 4b showed spatial pattern of landscape connectivity of ecological land patches across Beijing City. The large ecological land patches located in Yanqing District and Changping District, connecting the northern part of mountainous areas with its western part, had the most importance of landscape in view of the whole study area. Miyun District and Pinggu District were also concentrated with high landscape connectivity patches. In contrast, the ecological land patches located in the south of Beijing City and the surroundings of the city center were much smaller and often isolated, resulting in relatively low landscape connectivity.

As illustrated in Fig. 4c, spatial pattern of ecological land protection importance in the study area was characterized as high in the north, moderate in the southwest, and low in the central, east and south. In the city center (i.e. Dongcheng District, Xicheng District, Shijingshan District, Chaoyang District, Fengtai District and Haidian District), the ecological land protection importance were very low, while in mountainous areas it changed to moderate or high level. Furthermore, in the districts of Daxing, Tongzhou, Shunyi, Fangshan and Mentougou, ecological land protection importance were dominated by the levels of unimportant and general, with the accumulated area proportion over $50 \%$, and the level of very important for less than $5 \%$. In contrast, Pinggu District and Miyum District had the highest ecological land protection importance, with the level of very important accounting for $67.35 \%$ and $54.04 \%$ of the total area, respectively. Both districts occupied $58.34 \%$ of the highest level in the study area. 

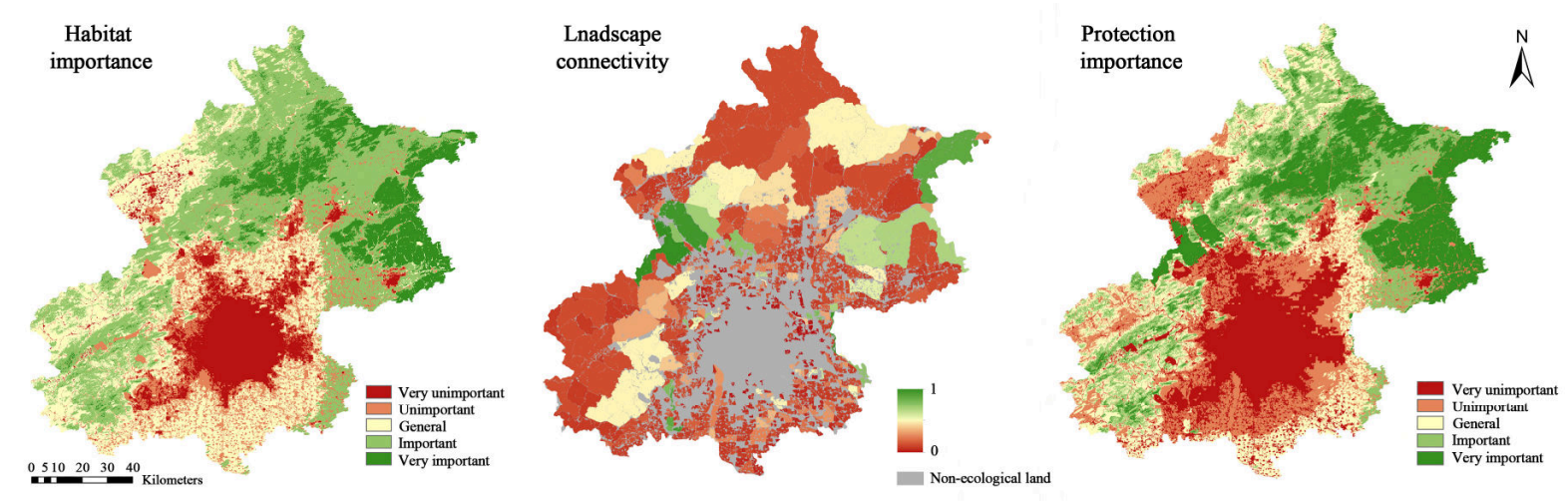

Fig.4 Spatial distribution of habitat importance, landscape connectivity, and protection importance of ecological land in Beijing City

Patches characterized with the highest level of ecological land protection importance, i.e. the level of very important, were identified as ecological sources in Beijing City. As shown in Fig.4c, more than a third of ecological sources were concentrated in Miyun District, covering an area of $1191.66 \mathrm{~km}^{2}$. Pinggu District and Huairou District ranked the second and third, with the area of $628.38 \mathrm{~km}^{2}$ and $597.70 \mathrm{~km}^{2}$, respectively. They were followed by Yanqing District and Changping District, accounting for about $8 \%$ of the total ecological sources. Although they were also mountainous districts, Mentougou District and Fangshan District were more affected by human activities due to relatively close to the city center, each occupied less than $3 \%$ of the ecological sources. In sum, there were $3119.65 \mathrm{~km}^{2}$ ecological sources in Beijing City, which were mainly distributed in the northeastern, northern and northwestern mountainous areas, while there were also sparsely distribution in the southwestern.

\subsection{Ecological corridors and restoration points}

The geometric centers of each patch of ecological sources, were extracted as ecological source points. Then, the direction lines of ecological corridors were identified based on the resistance surface using the tool boxes of Cost Distance, Cost Back Link, and Cost Path in ArcGIS 10.3 software (Fig. 5A). Moreover, the Buffer tool was applied to build up buffer zones with a radius of $900 \mathrm{~m}$ around the direction line of each ecological corridor, which corresponded with the search zones of the ant colony algorithm. Through applying the Euclidean Distance tool 
in ArcGIS 10.3 software, an Euclidean distance layer was constructed and reclassified into 31 categories (category codes from 0 to 30 ), with about $30 \mathrm{~m}$ difference between the two adjacent categories (Fig. 5B). Following the ant colony algorithm based methodological approach, the pixel direction information was obtained. Subsequently, the pixels characterized by very low pheromone were removed, and the pixels with the higher and the highest pheromone were merged, through setting the threshold in reclassification process. As a result, spatial pattern of pheromone at pixel scale was obtained, as shown in Fig. 5C. The pheromone pixels were then transformed into vector points in ArcGIS and the kernel density estimation tool was used for the analysis of variable-bandwidth kernel density estimation. Finally, the kernel density surface was divided into 9 categories by quantile, as shown in Fig. 5D.
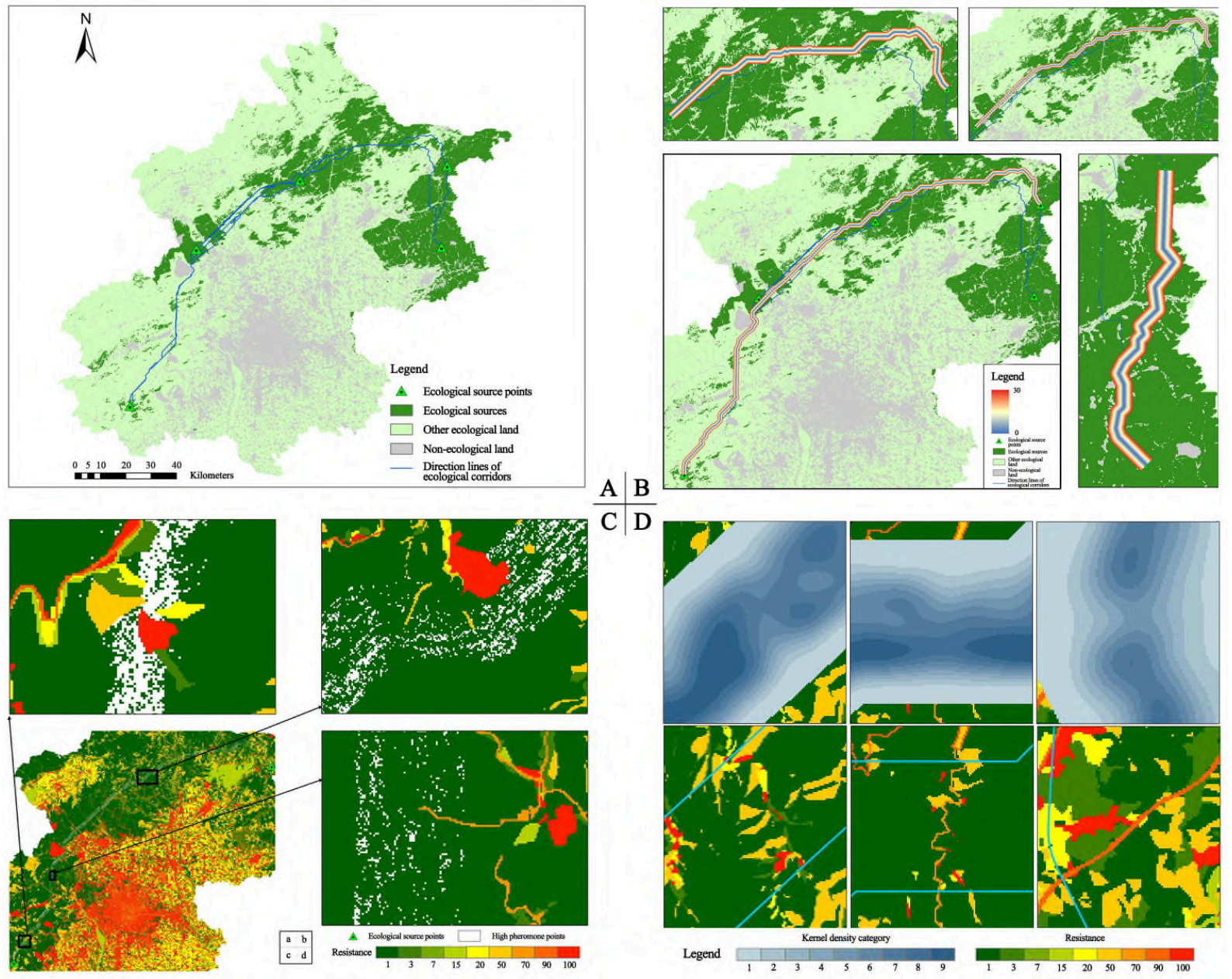

Fig.5 Ecological corridors identification process: (A) Identification of the direction lines of 
ecological corridors; (B) Reclassification of the Euclidean distance of ecological corridors' direction lines (Part of sample); (C) Detailed examples of spatial distribution of pheromone; (D) Detailed examples of kernel density categories

As to spatial distribution of pheromone, its relationship with spatial patterns of ecological resistance could be further explored in two different areas. Firstly, in the areas with local resistance patches having high fragmentation and clear heterogeneity (see Fig. 5C-a), it was notable that low resistance matrix was cut off directly by high resistance patches. Furthermore, points characterized by high pheromone often connected two low resistance patches following a narrow path situated in-between two high resistance patches. Secondly, in the areas that local resistance patches were relatively continuous and homogeneous (see Fig. 5C-b and Fig. 5C-d), spatial pattern of pheromone showed that before reaching high resistance patches, the pheromone points had been clearly compressed towards nearby low resistance patches. That was to say, the high pheromone points, representing the path that artificial ants would most probably follow, mainly appeared in the region with low resistance.

The kernel density surface showed that there were distinct differences among kernel density categories. Moreover, the highest three categories of kernel density surface could not only maintain their connectivity to a certain extent, but also show robust in behaving spatial morphological changes along the direction line of ecological corridor, such as the range and axial offset. Therefore, the highest three categories of kernel density surface, i.e. the categories of 7, 8 , and 9, could be selected to map the range of ecological corridors. In addition, in view of spatial distribution, mutation points or discontinuity points of different kernel density category appeared mainly as a result of high resistance patches cutting off the ecological corridors. These points were vital to moving efficiency in the ecological corridor, highly affected by human activities. Hence, defined as key restoration points, they were considered to be the key points in restoring ecological corridors.

In details, the most eastern ecological source point of all the five ecological source points 
were selected as the start point, with the most southwestern ecological source point for the end point. The total cumulative resistance of each ecological corridor's direction line, as being identified by MCR model, was considered as the total path length between two ecological source points. This information was used to apply the ant colony algorithm in order to identify the range and key restoration points of ecological corridors. Moreover, all the ecological corridors were distinguished into two categories. One was key ecological corridor, which was defined as the one with the lowest total cumulative resistance while connecting all ecological source points. All the other ecological corridors were defined as potential ecological corridor. Eventually, ecological security patterns in Beijing City, composed of ecological sources, key ecological corridor, potential ecological corridors, and key restoration points, were identified (Fig. 6).

In sum, the total area of key ecological corridor was $198.86 \mathrm{~km}^{2}$, with $567.30 \mathrm{~km}^{2}$ for potential ecological corridors. The majority of key ecological corridor, except for a small part in Miyun District, was closely surrounded by potential ecological corridors. The total area of potential ecological corridors was quite higher than that of key ecological corridor, because of rather larger range of the former. 34 ecological restoration points were also identified, mainly located at the intersections between ecological corridors and roads or isolated high resistance patches. Furthermore, spatial morphological characteristics of ecological corridors' range were quite different in the study area, especially between northwestern and northeastern parts. For example, the range of ecological corridors changed frequently in northeastern mountainous areas, with diverse directions of ecological corridors, because of unused land induced forest land fragmentation, and low limitation in ant colony path-finding resulting from low human disturbance. In contrast, there was only one ecological corridor with relative wider range in northwestern mountainous areas, connecting the northern mountains with the western mountains. This might be due to the relative small but aggregated forest land distributed between the city center and Yanqing District. 


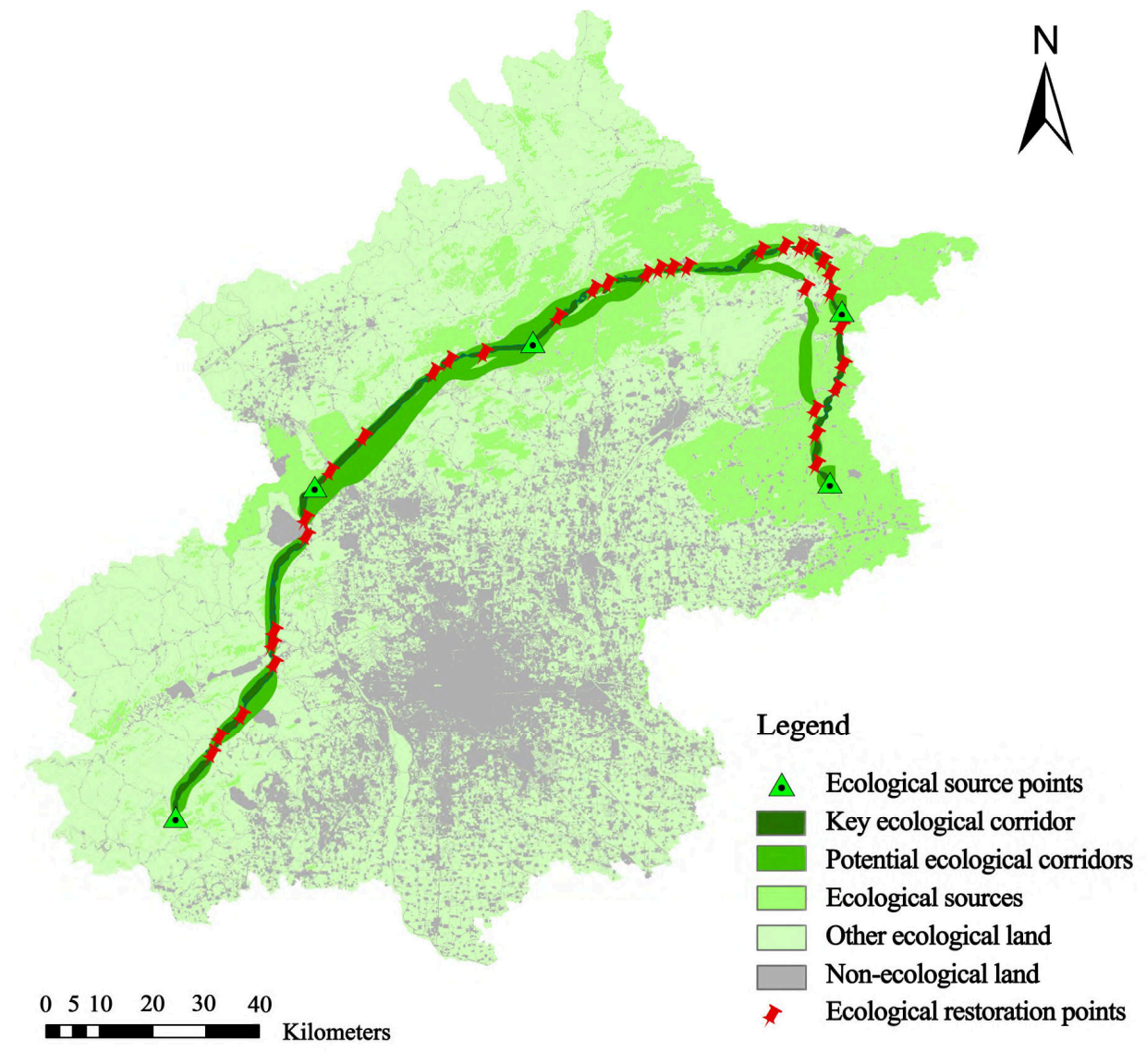

Fig.6 Ecological security patterns in Beijing City

\section{Discussion}

Identifying and maintaining ecological security patterns is vital to guarantee the integrity of ecosystem structure and processes at regional scale. Previous studies focused on ecological importance quantification and thus identifying spatial range of ecological sources, and the direction of ecological corridors. In this study, an approach integrating the methods of MCR, ant colony algorithm and kernel density estimation, was proposed to identify ecological security patterns with the spatial range of ecological sources and corridors, as well as key restoration points.

More specifically, the first advantage of the proposed approach, as compared to previous studies, is the identification of spatial range of ecological corridors as a result of combining the 
ant colony algorithm, with the kernel density estimation method. In previous studies, the range of ecological corridors were mostly determined through referring to the movement radius of target animals (Harrison et al., 1992; Lima et al., 1999). However, an important methodological limitation is the fact that this radius is regional and species dependency and it is hard to adjust when it is concerned with different region or species (Nathan et al., 2008; Zeller et al., 2014). In this study, this limitation was overcome by conducting a variable-bandwidth kernel density estimation in order to convert a discrete pheromone layer into a relatively smooth kernel density layer, which in turn, led to determine spatial range of the identified ecological corridors.

The second advantage of the proposed approach is to deliver a more complete ecological security patterns at regional scale, which were composed of not only ecological sources and corridors, but also key points for restoring ecological corridors. The identification of key restoration points may indicate the paradigm transformation of ecological security patterns study, i.e. from patch-corridor paradigm (representing by ecological sources and corridors) to patch-corridor-point paradigm (characterizing by ecological sources, corridors, and restoration points).

There were also some methodological disadvantages in this study. Firstly, ecological sources were identified according to the importance of ecosystem services and landscape connectivity. However, all the calculation was based on current status, without considering possible changes in the near future, especially ecosystem degradation due to human interferences in the urbanization (Peng et al., 2018). Moreover, in identifying spatial range of ecological corridors through combining the ant colony algorithm with kernel density estimation, the following two main issues should be further focused during data processing: (i) inaccuracy in the direction of local pixels to constrain the ant colony in an attempt to search for the optimal solution within the global solution space, and (ii) time efficiency in finding out the optimal solution due to the large spatial extent of input data. To address both issues, it is suggested to improve the direction organization of raster data and find out a more efficient machine learning algorithm. 


\section{Conclusions}

In this study, using GIS technology and spatial analysis models, important patches of ecological sources across Beijing City were identified according to habitat importance and landscape connectivity. Moreover, MCR, ant colony algorithm and kernel density estimation were integrated to identify spatial range and key restoration points of ecological corridors. Our results showed that the ecological sources were mainly located in the north, northwestern and northeastern part, with ecological corridors distributed along these ecological sources. In the northwestern part of the study area, ecological corridors were wide and fluent. However, in the northeastern there were diverse ecological corridors with changing range. Among all the identified ecological restoration points, the majority was located in the key ecological corridor. As both the ranges of ecological sources and corridors have been spatially identified, the protection of ecological security patterns can effectively enhance regional biodiversity and better protect endangered species. And the identified key restoration points can point out the priority area of ecological restoration. Therefore, the ant colony algorithm based approach proposed in this study can effectively identify ecological security patterns in megacities, with the detailed results serving as the spatial guideline for natural conservation and ecological restoration in urban planning of Beijing City.

\section{Acknowledgments}

This research was financially supported by the National Natural Science Foundation of China (41271195).

\section{References}

Aminzadeh, B., Khansefid, M., 2010. A case study of urban ecological networks and a sustainable city: Tehran's metropolitan area. Urban Ecosyst. 13, 23-36. https://doi.org/10.1007/s11252-009-0101-3

Asgarian, A., Amiri, B.J., Sakieh, Y., 2015. Assessing the effect of green cover spatial patterns on 
urban land surface temperature using landscape metrics approach. Urban Ecosyst. 18, 209222. https://doi.org/10.1007/s11252-014-0387-7

Bhowmik, A.K., Metz, M., Schäfer, R.B., 2015. An automated, objective and open source tool for stream threshold selection and upstream riparian corridor delineation. Environ. Model. Softw. 63, 240-250. https://doi.org/10.1016/j.envsoft.2014.10.017

Bonabeau, E., Dorigo, M., Theraulaz, G., 2000. Inspiration for optimization from social insect behaviour. Nature 406, 39-42. https://doi.org/10.1038/35017500

Brás, R., Cerdeira, J.O., Alagador, D., Araújo, M.B., 2013. Linking habitats for multiple species. Environ. Model. Softw. 40, 336-339. https://doi.org/10.1016/j.envsoft.2012.08.001

Brunsdon, C., 1995. Estimating probability surfaces for geographical point data: An adaptive kernel algorithm. Comput. Geosci. https://doi.org/10.1016/0098-3004(95)00020-9

Carranza, M.L., D’Alessandro, E., Saura, S., Loy, A., 2012. Connectivity providers for semi-aquatic vertebrates: The case of the endangered otter in Italy. Landsc. Ecol. 27, 281290. https://doi.org/10.1007/s10980-011-9682-3

Chen, S., Zha, X., 2016. Evaluation of soil erosion vulnerability in the Zhuxi watershed, Fujian Province, China. Nat. Hazards 82, 1589-1607. https://doi.org/10.1007/s11069-016-2258-4

Colorni, A., Dorigo, M., Maniezzo, V., Elettronica, D., Milano, P., 1991. Distributed Optimization by Ant Colonies. Ecal91, Eur. Conf. Artif. Life 134-142.

Cotter, M., Häuser, I., Harich, F.K., He, P., Sauerborn, J., Treydte, A.C., Martin, K., Cadisch, G., 2017. Biodiversity and ecosystem services-A case study for the assessment of multiple species and functional diversity levels in a cultural landscape. Ecol. Indic. 75, 111-117. https://doi.org/10.1016/j.ecolind.2016.11.038

Dorigo M., Gambardella L M., 1997. Ant colony system: a cooperative learning approach to the traveling salesman problem. IEEE Trans. Evol. Comput. 1(1): 53-66. https://doi.org/10.1109/4235.585892

Dorigo, M., Maniezzo, V., Colorni, A., 1996. Ant system: optimization by a colony of 
cooperating agents. IEEE Trans. IEEE Trans. Syst. Man, Cybern. Part B Cybern. 26(1), 29-41. https://doi.org/10.1109/3477.484436

Gao, Y., Ma, L., Liu, J., Zhuang, Z., Huang, Q., Li, M., 2017. Constructing Ecological Networks Based on Habitat Quality Assessment: A Case Study of Changzhou, China. Sci. Rep. 7, 111. https://doi.org/10.1038/srep46073

Golding, P., Kapadia, S., Naylor, S., Schulz, J., Maier, H.R., Lall, U., van der Velde, M., 2017. Framework for minimising the impact of regional shocks on global food security using multi-objective ant colony optimisation. Environ. Model. Softw. 95, 303-319. https://doi.org/10.1016/j.envsoft.2017.06.004

Harrison, R. L., 1992. Toward a theory of Inter - Refuge corridor design. Conserv. Biol. 6(2), 293-295. https://doi.org/10.1046/j.1523-1739.1992.620293.x

He, C., Liu, Z., Tian, J., Ma, Q., 2014. Urban expansion dynamics and natural habitat loss in China: A multiscale landscape perspective. Glob. Chang. Biol. 20, 2886-2902. https://doi.org/10.1111/gcb.12553

He, C., Zhang, D., Huang, Q., Zhao, Y., 2016. Assessing the potential impacts of urban expansion on regional carbon storage by linking the LUSD-urban and InVEST models. Environ. Model. Softw. 75, 44-58. https://doi.org/10.1016/j.envsoft.2015.09.015

Hepcan, Ç.C., Özkan, M.B., 2011. Establishing ecological networks for habitat conservation in the case of Çeşme-Urla Peninsula, Turkey. Environ. Monit. Assess. 174, 157-170. https://doi.org/10.1007/s10661-010-1447-y

Jenerette, G.D., Potere, D., 2010. Global analysis and simulation of land-use change associated with urbanization. Landsc. Ecol. 25, 657-670. https://doi.org/10.1007/s10980-010-9457-2

Jia, X., Fu, B., Feng, X., Hou, G., Liu, Y., Wang, X., 2014. The tradeoff and synergy between ecosystem services in the Grain-for-Green areas in Northern Shaanxi, China. Ecol. Indic. 43, 103-111. https://doi.org/10.1016/j.ecolind.2014.02.028

Kong, F., Ban, Y., Yin, H., James, P., Dronova, I., 2017. Modeling stormwater management at the city district level in response to changes in land use and low impact development. Environ. 
Model. Softw. 95, 132-142. https://doi.org/10.1016/j.envsoft.2017.06.021

Kong, F., Yin, H., Nakagoshi, N., Zong, Y., 2010. Urban green space network development for biodiversity conservation: Identification based on graph theory and gravity modeling. Landsc. Urban Plan. 95, 16-27. https://doi.org/10.1016/j.landurbplan.2009.11.001

Li, J., Song, C., Cao, L., Zhu, F., Meng, X., Wu, J., 2011. Impacts of landscape structure on surface urban heat islands: A case study of Shanghai, China. Remote Sens. Environ. 115, 3249-3263. https://doi.org/10.1016/j.rse.2011.07.008

Li, Y., Chan Hilton, A.B., 2007. Optimal groundwater monitoring design using an ant colony optimization paradigm. Environ. Model. Softw. 22, 110-116. https://doi.org/10.1016/j.envsoft.2006.05.023

Lima, M. G. D., Gascon, C., 1999. The conservation value of linear forest remnants in central Amazonia. Biol. Conserv. 91, 241-247. https://doi.org/10.1016/S0006-3207(99)00084-1

Lin, Y.P., Lin, W.C., Wang, Y.C., Lien, W.Y., Huang, T., Hsu, C.C., Schmeller, D.S., Crossman, N.D., 2017. Systematically designating conservation areas for protecting habitat quality and multiple ecosystem services. Environ. Model. Softw. 90, 126-146. https://doi.org/10.1016/j.envsoft.2017.01.003

Long, Y., Han, H., Lai, S.K., Mao, Q., 2013. Urban growth boundaries of the Beijing Metropolitan Area: Comparison of simulation and artwork. Cities 31, 337-348. https://doi.org/10.1016/j.cities.2012.10.013

Mandle, L., Douglass, J., Lozano, J.S., Sharp, R.P., Vogl, A.L., Denu, D., Walschburger, T., Tallis, H., 2016. OPAL: An open-source software tool for integrating biodiversity and ecosystem services into impact assessment and mitigation decisions. Environ. Model. Softw. 84, 121133. https://doi.org/10.1016/j.envsoft.2016.06.008

Nathan, R., Getz, W. M., Revilla, E., Holyoak, M., Kadmon, R., Saltz, D., Smouse, P. E., 2008. A movement ecology paradigm for unifying organismal movement research. Proc Natl Acad Sci U S A. 105(49):19052-9. https://doi.org/10.1073/pnas.0800375105

Nguyen, D.C.H., Ascough, J.C., Maier, H.R., Dandy, G.C., Andales, A.A., 2017. Optimization of 
irrigation scheduling using ant colony algorithms and an advanced cropping system model. Environ. Model. Softw. 97, 32-45. https://doi.org/10.1016/j.envsoft.2017.07.002

Nowak, D.J., Hirabayashi, S., Bodine, A., Hoehn, R., 2013. Modeled PM2.5 removal by trees in ten U.S. cities and associated health effects. Environ. Pollut. 178, 395-402. https://doi.org/10.1016/j.envpol.2013.03.050

Parks, S.A., Mckelvey, K.S., Schwartz, M.K., 2013. Effects of Weighting Schemes on the Identification of Wildlife Corridors Generated with Least-Cost Methods. Conserv. Biol. 27, 145-154. https://doi.org/10.1111/j.1523-1739.2012.01929.x

Peng, J., Du, Y., Ma, J., Liu, Z., Liu, Y., Wei, H., 2015. Sustainability evaluation of natural capital utilization based on 3DEF model: A case study in Beijing City, China. Ecol. Indic. 58, 254-266. https://doi.org/10.1016/j.ecolind.2015.06.002

Peng, J., Pan, Y., Liu, Y., Zhao, H., Wang, Y., 2018. Linking ecological degradation risk to identify ecological security patterns in a rapidly urbanizing landscape. Habitat Int. 71, 110 124. https://doi.org/10.1016/j.habitatint.2017.11.010

Peng, J., Shen, H., Wu, W., Liu, Y., Wang, Y., 2016. Net primary productivity (NPP) dynamics and associated urbanization driving forces in metropolitan areas: a case study in Beijing City, China. Landsc. Ecol. 31, 1077-1092. https://doi.org/10.1007/s10980-015-0319-9

Peng, J., Tian, L., Liu, Y., Zhao, M., Hu, Y., Wu, J., 2017. Ecosystem services response to urbanization in metropolitan areas: Thresholds identification. Sci. Total Environ. 607-608, 706-714. https://doi.org/10.1016/j.scitotenv.2017.06.218

Pierik, M.E., Dell'acqua, M., Confalonieri, R., Bocchi, S., Gomarasca, S., 2016. Designing ecological corridors in a fragmented landscape: A fuzzy approach to circuit connectivity analysis. Ecol. Indic. 67, 807-820. https://doi.org/10.1016/j.ecolind.2016.03.032

Polasky, S., Nelson, E., Pennington, D., Johnson, K.A., 2011. The impact of land-use change on ecosystem services, biodiversity and returns to landowners: A case study in the state of Minnesota. Environ. Resour. Econ. 48, 219-242. https://doi.org/10.1007/s10640-010-9407-0 
Rockström, J., Steffen, W., Noone, K., Persson, Å., Chapin, F.S., Lambin, E., Lenton, T.M., Scheffer, M., Folke, C., Schellnhuber, H.J., Nykvist, B., de Wit, C.A., Hughes, T., van der Leeuw, S., Rodhe, H., Sörlin, S., Snyder, P.K., Costanza, R., Svedin, U., Falkenmark, M., Karlberg, L., Corell, R.W., Fabry, V.J., Hansen, J., Walker, B., Liverman, D., Richardson, K., Crutzen, P., Foley, J., 2009. Planetary boundaries: Exploring the safe operating space for humanity. Ecol. Soc. 14. https://doi.org/10.5751/ES-03180-140232

Rouget, M., Cowling, R.M., Lombard, A.T., Knight, A.T., Kerley, G.I.H., 2006. Designing large-scale conservation corridors for pattern and process. Conserv. Biol. 20, 549-561. https://doi.org/10.1111/j.1523-1739.2006.00297.x

Rozos, D., Skilodimou, H.D., Loupasakis, C., Bathrellos, G.D., 2013. Application of the revised universal soil loss equation model on landslide prevention. An example from N. Euboea (Evia) Island, Greece. Environ. Earth Sci. 70, 3255-3266. https://doi.org/10.1007/s12665-013-2390-3

Sharp, R., Tallis, H.T., Ricketts, T., et al., 2018. InVEST 3.5.0.post270+hfc0c918079cb User's Guide. The Natural Capital Project, Stanford University, University of Minnesota, The Nature Conservancy, and World Wildlife Fund.

Shi, X., 2010. Selection of bandwidth type and adjustment side in kernel density estimation over inhomogeneous backgrounds. Int. J. Geogr. Inf. Sci. 24, 643-660. https://doi.org/10.1080/13658810902950625

Su, Y., Chen, X., Liao, J., Zhang, H., Wang, C., Ye, Y., Wang, Y., 2016. Modeling the optimal ecological security pattern for guiding the urban constructed land expansions. Urban For. Urban Green. 19, 35-46. https://doi.org/10.1016/j.ufug.2016.06.013

Teng, M., Wu, C., Zhou, Z., Lord, E., Zheng, Z., 2011. Multipurpose greenway planning for changing cities: A framework integrating priorities and a least-cost path model. Landsc. Urban Plan. 103, 1-14. https://doi.org/10.1016/j.landurbplan.2011.05.007

Van Oost, K., Govers, G., Desmet, P., 2000. Evaluating the effects of changes in landscape structure on soil erosion by water and tillage. Landsc. Ecol. 15, 577-589. 


\section{https://doi.org/10.1023/A:1008198215674}

Vergnes, A., Kerbiriou, C., Clergeau, P., 2013. Ecological corridors also operate in an urban matrix: A test case with garden shrews. Urban Ecosyst. 16, 511-525. https://doi.org/10.1007/s11252-013-0289-0

Wang, S., Ma, H., Zhao, Y., 2014. Exploring the relationship between urbanization and the eco-environment - A case study of Beijing-Tianjin-Hebei region. Ecol. Indic. 45, 171-183. https://doi.org/10.1016/j.ecolind.2014.04.006

Wang, Y.H., Yang, K.C., Bridgman, C.L., Lin, L.K., 2008. Habitat suitability modelling to correlate gene flow with landscape connectivity. Landsc. Ecol. 23, 989-1000. https://doi.org/10.1007/s10980-008-9262-3

Wu, Z., Wu, J., Liu, J., He, B., Lei, T., Wang, Q., 2013. Increasing terrestrial vegetation activity of ecological restoration program in the Beijing-Tianjin Sand Source Region of China. Ecol. Eng. 52, 37-50. https://doi.org/10.1016/j.ecoleng.2012.12.040

Yu, K., 1996. Security patterns and surface model in landscape ecological planning. Landsc. Urban Plan. 36, 1-17. https://doi.org/10.1016/S0169-2046(96)00331-3

Zeller, K.A., McGarigal, K., Beier, P., Cushman, S.A., Vickers, T.W., Boyce, W.M., 2014. Sensitivity of landscape resistance estimates based on point selection functions to scale and behavioral state: Pumas as a case study. Landsc. Ecol. 29, 541-557. https://doi.org/10.1007/s10980-014-9991-4

Zhang, W., Gong, X., Han, G., Zhao, Y., 2017a. An improved ant colony algorithm for path planning in one scenic area with many spots. IEEE Access, PP (99), 1-1.

Zhang, L., Peng, J., Liu, Y., Wu, J., 2017b. Coupling ecosystem services supply and human ecological demand to identify landscape ecological security pattern: A case study in Beijing-Tianjin-Hebei region, China. Urban Ecosyst. 20, 701-714. https://doi.org/10.1007/s11252-016-0629-y

Zhao, X.Q., Xu, X.H., 2015. Research on landscape ecological security pattern in a Eucalyptus introduced region based on biodiversity conservation. Russ. J. Ecol. 46, 59-70. 
https://doi.org/10.1134/S106741361501018X 